\title{
Wafer Level Solid Liquid Interdiffusion Bonding: Formation and Evolution of Microstructures
}

\author{
V. VUORINEN ${ }^{1,}{ }^{1,2}$ H. DONG,${ }^{1}$ G. ROSS, ${ }^{1}$ J. HOTCHKISS, ${ }^{1}$ J. KAAOS, ${ }^{1}$ \\ and M. PAULASTO-KRÖCKEL ${ }^{1}$ \\ 1.-Department of Electrical Engineering and Automation, School of Electrical Engineering, Aalto \\ University, PO Box 13340, 00076 Aalto, Finland. 2.—e-mail: Vesa.Vuorinen@tkk.fi
}

\begin{abstract}
Wafer-level solid liquid interdiffusion (SLID) bonding, also known as transient liquid-phase bonding, is becoming an increasingly attractive method for industrial usage since it can provide simultaneous formation of electrical interconnections and hermetic encapsulation for microelectromechanical systems. Additionally, SLID is utilized in die-attach bonding for electronic power components. In order to ensure the functionality and reliability of the devices, a fundamental understanding of the formation and evolution of interconnection microstructures, as well as global and local stresses, is of utmost importance. In this work a low-temperature Cu-In-Sn based SLID bonding process is presented. It was discovered that by introducing In to the traditional $\mathrm{Cu}-\mathrm{Sn}$ metallurgy as an additional alloying element, it is possible to significantly decrease the bonding temperature. Decreasing the bonding temperature results in lower CTE induced global residual stresses. However, there are still several open issues to be studied regarding the effects of dissolved In on the physical properties of the $\mathrm{Cu}-\mathrm{Sn}$ intermetallics. Additionally, partially metastable microstructures were observed in bonded samples that did not significantly evolve during thermal annealing. This indicates the $\mathrm{Cu}-\mathrm{In}-\mathrm{Sn}$ SLID bond microstructure is extremely stable.
\end{abstract}

Key words: Low-temperature SLID bonding, TLP bonding, $\mathrm{Cu}-\mathrm{In}$-Sn system, reliability

\section{INTRODUCTION}

Functional structures used in microelectromechanical systems (MEMS/MOEMS) must be electrically connected and hermetically encapsulated. Wafer-level bonding though 3D-integration enables multi-sensor fusion with logic in a vertical highspeed package. Solid liquid interdiffusion (SLID) bonding, also known as transient liquid-phase (TLP) bonding, is becoming an increasingly attractive method for wafer level packaging of MEMS/ MOEMS devices. ${ }^{1-5}$ SLID bonding offers several technological advantages for the development of

(Received July 18, 2020; accepted September 25, 2020;

published online October 20, 2020) reliable wafer-level packaging. These advantages include lower bonding temperature by utilizing a low melting point metal that ultimately results in a bond with a much higher re-melting temperature, large reduction of the required bonding footprint, integrated hermeticity and, integration of vertical electrical interconnects using through silicon vias (TSVs). The low $\left(T<350^{\circ} \mathrm{C}\right)$ bonding temperatures enable packaging of temperature sensitive materials, and minimize residual stresses when bonding materials with different thermomechanical properties, such as the coefficient of thermal expansion (CTE) (e.g. glass or germanium windows to optical Si MEMS devices, or large dies to ceramic substrates in power electronic applications).

The formation of the bond in the SLID process occurs in four consecutive stages: (1) melting of the 
low-melting temperature metal (i.e. Sn or In), (2) rapid dissolution of the high melting temperature metal (i.e. $\mathrm{Ag}, \mathrm{Au}, \mathrm{Cu}, \mathrm{Co}$ or $\mathrm{Ni}$ ), (3) intermetallic compounds (IMCs) formation that leads to isothermal solidification and (4) homogenization of the interconnection structure. Au-Sn and $\mathrm{Cu}-\mathrm{Sn}$ based metallurgies are the most commonly utilized material options for SLID out of the several different demonstrated binary systems; Ag-In, ${ }^{6-8} \mathrm{Au}-\mathrm{In},{ }^{3,9-14}$ $\mathrm{Cu}-\mathrm{In},{ }_{15} \mathrm{Ag}-\mathrm{Sn},{ }^{16,17} \mathrm{Ni}-\mathrm{Sn},{ }^{3,18-20} \mathrm{Au}-\mathrm{Sn}^{21-28}$ and $\mathrm{Cu}-\mathrm{Sn} .{ }^{5,29-38} \mathrm{Au}-\mathrm{Sn}$ and $\mathrm{Cu}-\mathrm{Sn}$ systems have been demonstrated to form mechanically and chemically reliable bonds at bonding temperatures close to $300^{\circ} \mathrm{C} .^{39-42}$ However, there is only a limited amount of information available on ternary and higher order SLID systems that can provide additional benefits, such as even lower processing temperatures or enhanced physical properties for higher functional performance and long-term reliability. Due to its low melting temperature $\left(T_{\mathrm{M}}=156.6^{\circ} \mathrm{C}\right)$ and known compatibility with the commonly used metallizations in electronics, indium has been widely utilized in low-temperature lead free solders. ${ }^{43,44}$ Therefore, it can be considered as a potential additive element for $\mathrm{Cu}$-Sn based SLID metallurgy, but the actual effects on the mechanical reliability performance must be studied in detail.

The objective of this study is to investigate the novel $\mathrm{Cu}-\mathrm{In}$-Sn based metallurgy for low-temperature SLID bonding. Moreover, the formation and evolution of microstructures is examined by utilizing thermodynamic calculations. ${ }^{45-47}$ The stabilizing effect (i.e. the higher (more negative) value for Gibbs energy of formation) of In on Cu-Sn IMCs of $\mathrm{Cu}_{6} \mathrm{Sn}_{5}$ and $\mathrm{Cu}_{3} \mathrm{Sn}$ is analysed and the effects on chemical potentials and driving forces diffusion are discussed. ${ }^{46,47}$

\section{MATERIALS AND METHODS}

The SLID bonding experiments were carried out using 4 " double side polished (DSP) Si wafers with a (100) crystal orientation. The backsides of the wafers were patterned using a standard lithography process and the $\mathrm{Si}$ was etched using reactive ion etching (RIE). A $30 \mathrm{~nm}$ TiW barrier/adhesion layer followed by a $\mathrm{Cu}$ seed-layer of $150 \mathrm{~nm}$ was sputtered on the frontside of all wafers. A standard lithography process was utilized for the patterning of microbumps with dimensions ranging from $10 \mu \mathrm{m} \times 10$ $\mu \mathrm{m}$ up to $250 \mu \mathrm{m} \times 250 \mu \mathrm{m}$. Subsequently, a targeted thickness of $4 \mu \mathrm{m}$ of Cu, $2 \mu \mathrm{m}$ of Sn and $2 \mu \mathrm{m}$ of In was electrochemically deposited on both wafers. Then the photoresist was stripped, and the field metallization layers were etched by means of wet chemistry. Low temperature bonding experiments (see Fig. 1) were conducted using different bonding temperatures $\left(200^{\circ} \mathrm{C}\right.$ and $\left.250^{\circ} \mathrm{C}\right)$ for a fixed time of $1 \mathrm{~h}$ and a fixed pressure of $18 \mathrm{MPa}$. Wafers were placed into the AML-AWB-04 wafer bonder and rough aligned at ambient temperature and pressure. The bonding chamber was pumped down and then preheated to $75^{\circ} \mathrm{C}\left(T_{\mathrm{H}}\right)$ before carrying out fine alignment. Contact was made after alignment and then the desired bonding pressure of $18 \mathrm{MPa}\left(P_{\mathrm{B}}\right)$ was applied. A controlled heating of cycle of $20^{\circ} \mathrm{C} / \mathrm{s}$ was initiated until the desired bonding temperature was obtained. The wafers were held at the target bonding temperature $\left(T_{\mathrm{B}}\right)$ and pressure for $60 \mathrm{~min}\left(t_{\mathrm{b}}-t_{\mathrm{c}}\right)$. After the bonding time had expired the heaters were switched off and the bonding pressure was released. The wafers were allowed to cool for approximately $1 \mathrm{~h}$ until they had reached about $150^{\circ} \mathrm{C}$ temperature before venting the bonding chamber and removing the bonded wafer pair. Dicing of the bonded wafers was conducted using a Disco DAD3220 dicing saw.

The high temperature storage (HTS) aging test at $150^{\circ} \mathrm{C}$ was conducted with a Heraeus Instruments oven for up to $1000 \mathrm{~h}$ for the diced chips. For the microstructural analysis, samples were cross-sectioned with standard metallographic methods. JEOL JSM-6330F field emission scanning electron microscope (SEM) with back-scattered electrons detector (BSE) and Oxford Instruments INCA Xsight energy-dispersive $\mathrm{x}$-ray spectroscopy (EDX) equipment were used for the detailed microstructural analysis. The composition of phases was determined by averaging measurements from a minimum of 5 different locations with EDX.

The thermodynamic description of $\mathrm{Cu}-\mathrm{In}$-Sn has been critically optimized in Ref.45 by performing thermodynamic modelling and experimental investigations on the phase equilibria. In this work, the thermodynamic parameters of $\mathrm{Cu}-\mathrm{In}-\mathrm{Sn}$ are according to the work of Liu et al. Ref.45 The relevant phase diagrams and thermodynamic properties were calculated by using the Poly calculation module packaged in the Thermo-Calc software package. $^{48}$

\section{RESULTS AND DISCUSSION}

- Indium as a low melting point metal $\left(T_{\mathrm{m}}=\right.$ $156.6^{\circ} \mathrm{C}$ ) ha as significant stabilizing effect on the liquid phase in a Cu-Sn system. On the other hand, In also dissolves in Cu-Sn intermetallics and, thus, increases their thermal stability. These effects are illustrated in Fig. 2, where a vertical section (see Fig. 2b) along the expected contact line (CL) (see Fig. 2a) from 50Sn50In (at.\%) to $\mathrm{Cu}$ is presented. It is known that the local nominal composition (LNC), i.e. the average chemical composition of the reaction zone, follows the contact line. The melting temperature of the bond as a function of $\mathrm{Cu}$ content is highlighted in Fig. $1 \mathrm{~b}$ with a dotted line. It is obvious that a liquid phase is present at the ternary eutectic temperature $\left(T=110^{\circ} \mathrm{C}\right)$ when the $\mathrm{LNC}$ of $\mathrm{Cu}$ is less than 55 at.\%. However, the melting temperature increases rapidly up to 
(a)

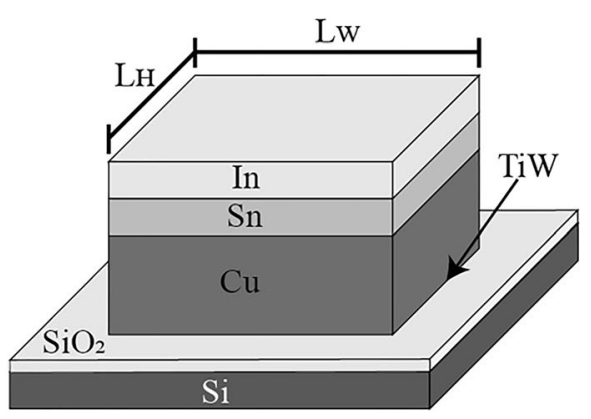

(b) Temperature-Pressure-Time Profile

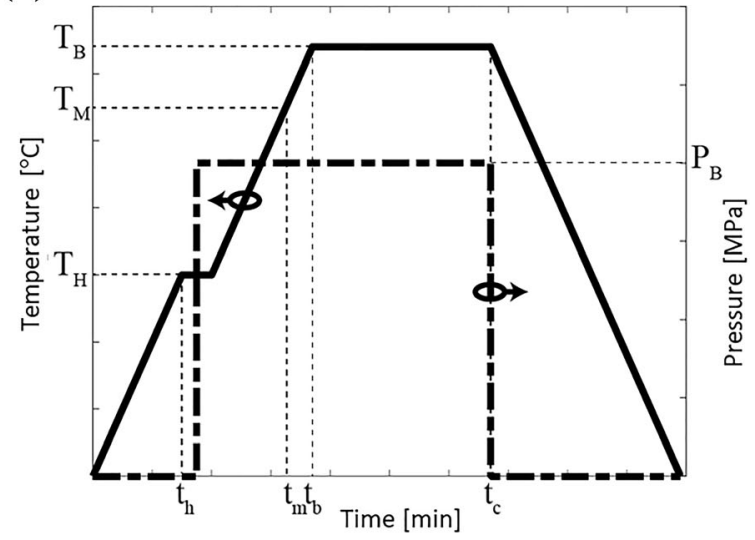

Fig. 1. (a) Micro-bump structure from one side before bonding, (b) bonding profile.

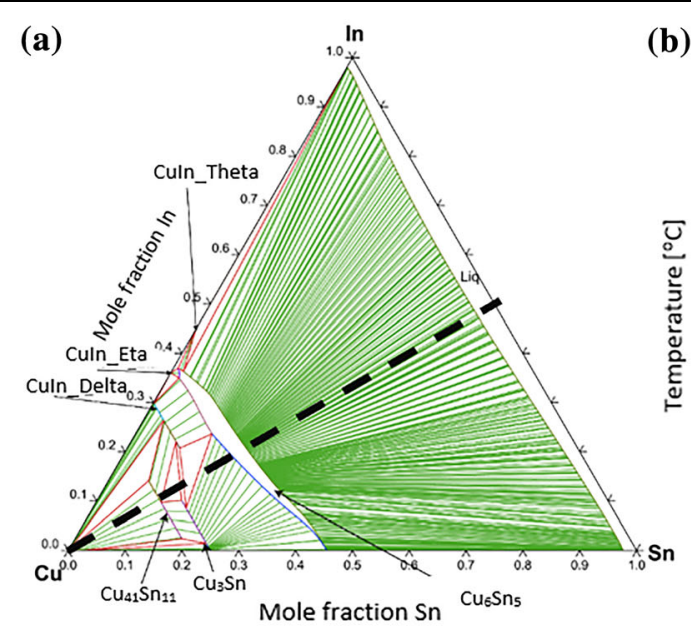

(c)

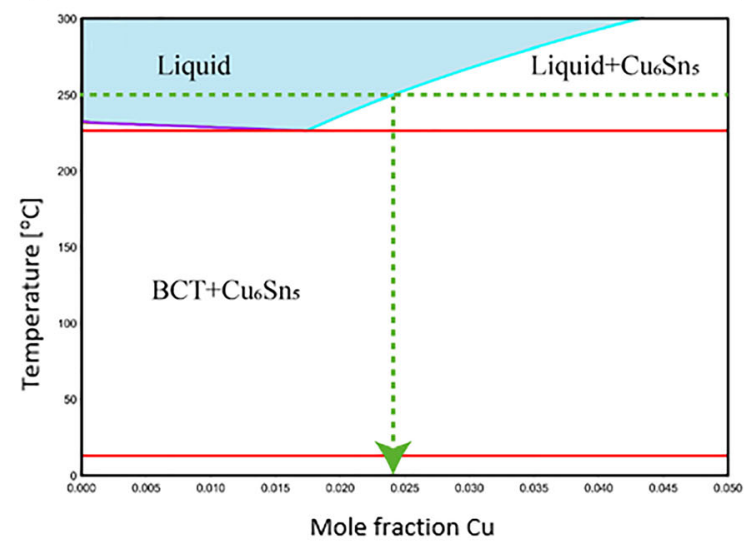

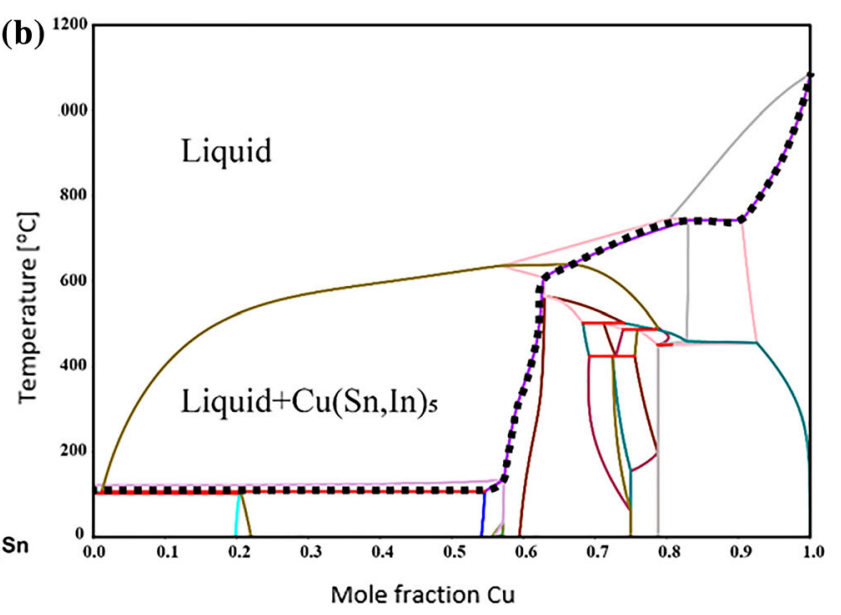

(d)

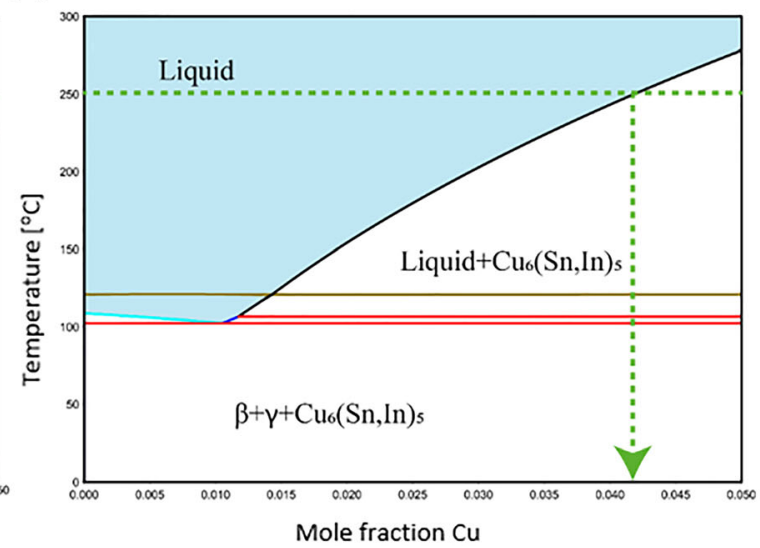

Fig. 2. (a) Cu-In-Sn $250^{\circ} \mathrm{C}$ isothermal section with superimposed dashed contact-line, (b) vertical section from 50Sn50ln (at.\%) to pure Cu, (c) enlarged area from eutectic point in binary Cu-Sn phase diagram, and (d) corresponding area from ternary Cu-In-Sn system.

$600^{\circ} \mathrm{C}$ when the $\mathrm{Cu}$ content exceeds 60 at. $\%$. Therefore, by incorporating In as a ternary alloying element into a Cu-Sn binary system, both lower bonding and higher re-melting temperatures can be obtained. The drastically enlarged bonding process window is highlighted with light-blue in Fig. 2c and d, where a magni- fied image from the eutectic point in a binary $\mathrm{Cu}$ $\mathrm{Sn}$ system is compared to that of a ternary $\mathrm{Cu}$ In-Sn system. As shown by the green dotted lines, the solubility of $\mathrm{Cu}$ into the liquid phase doubles when In is added to the system. On the other hand, the same $\mathrm{Cu}$ solubility may be obtained under significantly $\left(>50^{\circ} \mathrm{C}\right)$ lower 
bonding temperatures. The solubility of $\mathrm{Cu}$ in liquid is an essential parameter affecting the reaction kinetics to be modified, as it defines the dissolution rate and, therefore, the initial formation of the intermetallics, which in turn controls the total duration of the bonding process.

Figure 3 shows the interconnection microstructures after bonding at temperatures of $250^{\circ} \mathrm{C}$ and $200^{\circ} \mathrm{C}$ for $1 \mathrm{~h}$. In Fig. 4 the corresponding microstructures are presented after subsequent annealing at $150^{\circ} \mathrm{C}$ for $1000 \mathrm{~h}$. As can be seen from the Fig. 3, the total thickness of the bond, i.e. residual $\mathrm{Cu}$ and IMC layers, is about $10 \mu \mathrm{m}$, and the thickness of the IMC layers is about $3 \mu \mathrm{m}$ after both bonding processes. When comparing these values to initial target thicknesses, it is obvious that some squeeze-out has occurred. However, no residual Sn or In was observed. After bonding at $250^{\circ} \mathrm{C}$ for $1 \mathrm{~h}$, the IMC microstructure was mainly composed of $\mathrm{Cu}_{3}(\mathrm{Sn}, \mathrm{In})$ phase with the average composition of Cu74.6 Sn 14.7 In $10.7 \pm 0.5$ at.\%. In addition, some
$\mathrm{Cu}_{6}(\mathrm{Sn}, \mathrm{In})_{5}$ phase with the average composition of Cu54.1 Sn 23.2 In $22.7 \pm 0.5$ at.\% was also detected in the middle part of the bond. Nevertheless, it is to be noted that the Sn to In ratio can't be unambiguously defined due to the resolution limitations of the EDS method. On the other hand, the $200^{\circ} \mathrm{C}$ bond microstructure is composed mainly of a $\mathrm{Cu}_{6}(\mathrm{Sn}, \mathrm{In})_{5}$ phase with the average composition of Cu54.0 Sn 24.0 In $22.0 \pm 0.5$ at.\%. Additionally, a very thin layer of presumably $\mathrm{Cu}_{3}(\mathrm{Sn}, \mathrm{In})$ phase with some voids can be seen at the interface between $\mathrm{Cu}_{6}(\mathrm{~S}$ $\mathrm{n}$,In $)_{5}$ and $\mathrm{Cu}$. Interestingly, it seems that the asbonded microstructure is extremely stable and only minor changes can be observed, even after extensive solid state annealing (see Fig. 4). Some local $\mathrm{Cu}_{6}(\mathrm{Sn}, \mathrm{In})_{5}$ precipitates can still be detected from the sample that was bonded at $250^{\circ} \mathrm{C}$ and annealed at $150^{\circ} \mathrm{C}$ for $1000 \mathrm{~h}$. Additionally, in the sample that was originally bonded at $200 \mathrm{C}$ and then annealed at $150^{\circ} \mathrm{C}$ for $1000 \mathrm{~h}$ the thickness of the $\mathrm{Cu}_{3}(\mathrm{Sn}, \mathrm{In})$ is still clearly below $0.5 \mu \mathrm{m}$.

In order to understand the observed microstructures, the diffusion path concept can be used. The isothermal section from the $\mathrm{Cu}-\mathrm{Sn}$-In system at
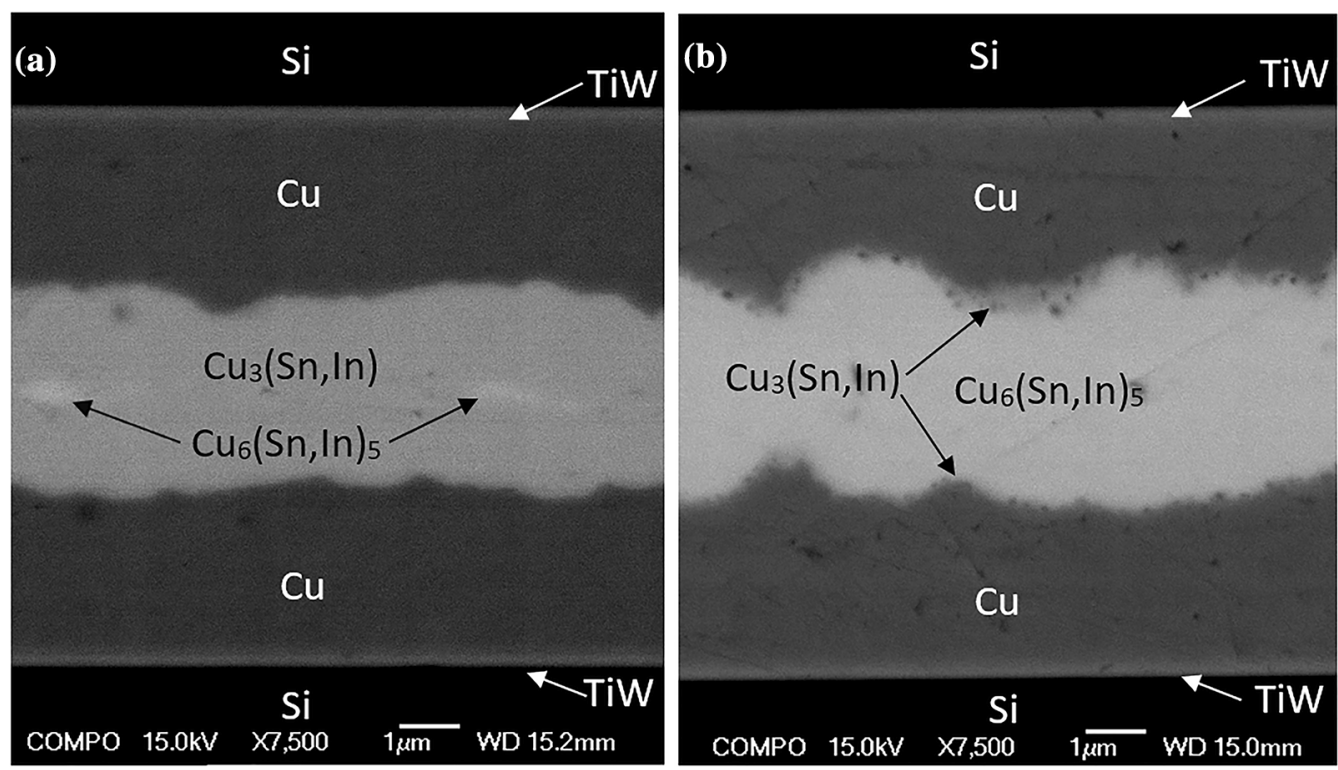

Fig. 3. As-bonded microstructures from (a) $250^{\circ} \mathrm{C}$ and (b) $200^{\circ} \mathrm{C}$.
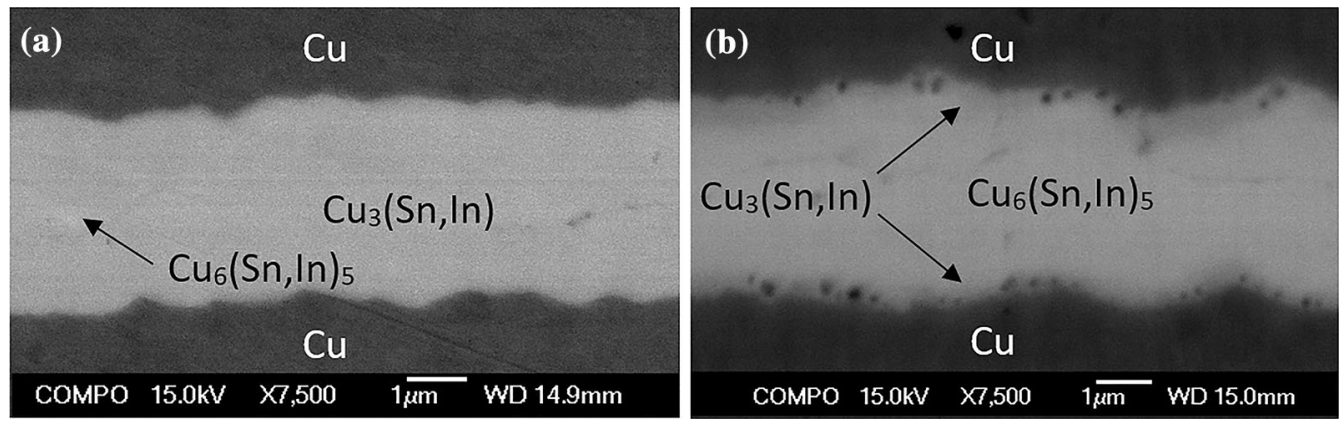

Fig. 4. Microstructures after initial bonding (a) at $250^{\circ} \mathrm{C}$ and (b) at $200^{\circ} \mathrm{C}$ for $1 \mathrm{~h}$, and subsequently annealing at $150^{\circ} \mathrm{C}$ for $1000 \mathrm{~h}$. 
$250^{\circ} \mathrm{C}$ is presented in Fig. 5 with superimposed contact line and estimated diffusion path, which obeys the mass balance. Based on the microstructure, it can be concluded that the local nominal composition of the bond is clearly above 60 at. $\% \mathrm{Cu}$, i.e. the expected melting temperature of the bond is $>600^{\circ} \mathrm{C}$. The isothermal section at $200^{\circ} \mathrm{C}$ is almost identical to that of $250^{\circ} \mathrm{C}$, with the exception of a slightly smaller liquid phase area, and therefore it is not presented here.

Based on the assessed thermodynamic data from the $\mathrm{Cu}-\mathrm{In}$-Sn system it is possible to analyse the effects of In addition on the stabilities of $\mathrm{Cu}-\mathrm{Sn}$

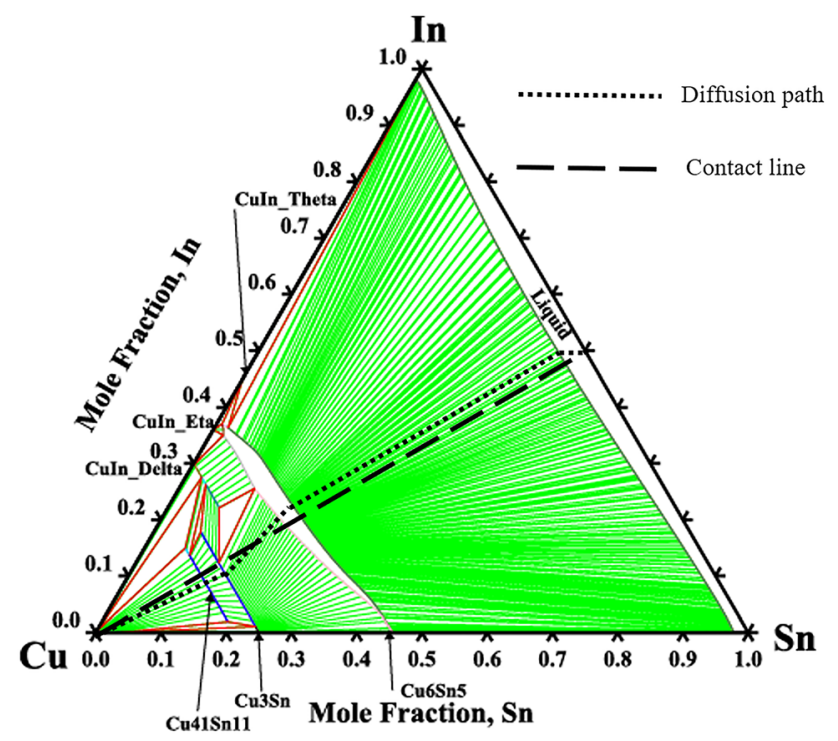

Fig. 5. Isothermal section from Cu-Sn-In system at $250^{\circ} \mathrm{C}$, with superimposed dashed contact line $(\mathrm{CL})$ and dotted diffusion path. intermetallics, chemical potentials at different stable or metastable local equilibria, and thus the driving forces for diffusion and subsequent chemical reactions. The Gibbs energies at $250^{\circ} \mathrm{C}$ of pure $\mathrm{Cu}_{6} \mathrm{Sn}_{5}$ and $\mathrm{Cu}_{3} \mathrm{Sn}$ phases, together with to those of ternary ones $\mathrm{Cu}_{6}(\mathrm{Sn}, \mathrm{In})_{5}$ and $\mathrm{Cu}_{3}(\mathrm{Sn}, \mathrm{In})$, as well as binary and ternary liquid phases, are presented in Fig. 6. Note that the tie-lines in the ternary system may not be in the vertical section, therefore, the Gibbs energy values, used in Fig. 6 for illustrative purposes, are taken from the corresponding local equilibria and the IMCs are marked according to local equilibria Gibbs energy values. The equivalent chemical potentials at the binary $\mathrm{Cu}-\mathrm{Sn}$ and ternary $\mathrm{Cu}-\mathrm{In}-\mathrm{Sn}$ systems are shown in Table I. These values were calculated by using the solid-state stabile structures as reference states e.g. Fcc for $\mathrm{Cu}$, Bct for Sn and Tetra for In.

Based on Fig. 6 and Table $I$ it is obvious that indium has a much stronger relative stabilizing effect on the $\mathrm{Cu}_{6} \mathrm{Sn}_{5}$ phase than on the $\mathrm{Cu}_{3} \mathrm{Sn}$ phase. With the observed amount of dissolved indium in these IMCs, the Gibbs energy of formation for $\mathrm{Cu}_{6} \mathrm{Sn}_{5}$ phase has increased much more ( $\sim 50 \%)$ than that of the $\mathrm{Cu}_{3} \mathrm{Sn}$ phase $(\sim 10 \%)$. Hence, the driving force (i.e. chemical potential difference) for $\mathrm{Cu}$ atoms to diffuse through the IMC reaction layers is drastically reduced when indium is added to the system. For example, the dotted and dash-dotted lines in Fig. 6 indicate the local $\mathrm{Cu}_{3} \mathrm{Sn}$ $\mathrm{Cu}_{6} \mathrm{Sn}_{5}$ phase equilibria in binary and ternary systems, respectively. Based on these it is evident that the chemical potential difference from pure $\mathrm{Cu}$ to this interface is, in binary system $\left(\Delta \mu_{\mathrm{Cu}}^{\mathrm{I}}=9700 \mathrm{~J} / \mathrm{mol}\right)$, almost three times as large as in ternary system $\left(\Delta \mu_{\mathrm{Cu}}^{\mathrm{II}}=3510 \mathrm{~J} / \mathrm{mol}\right)$. Similar

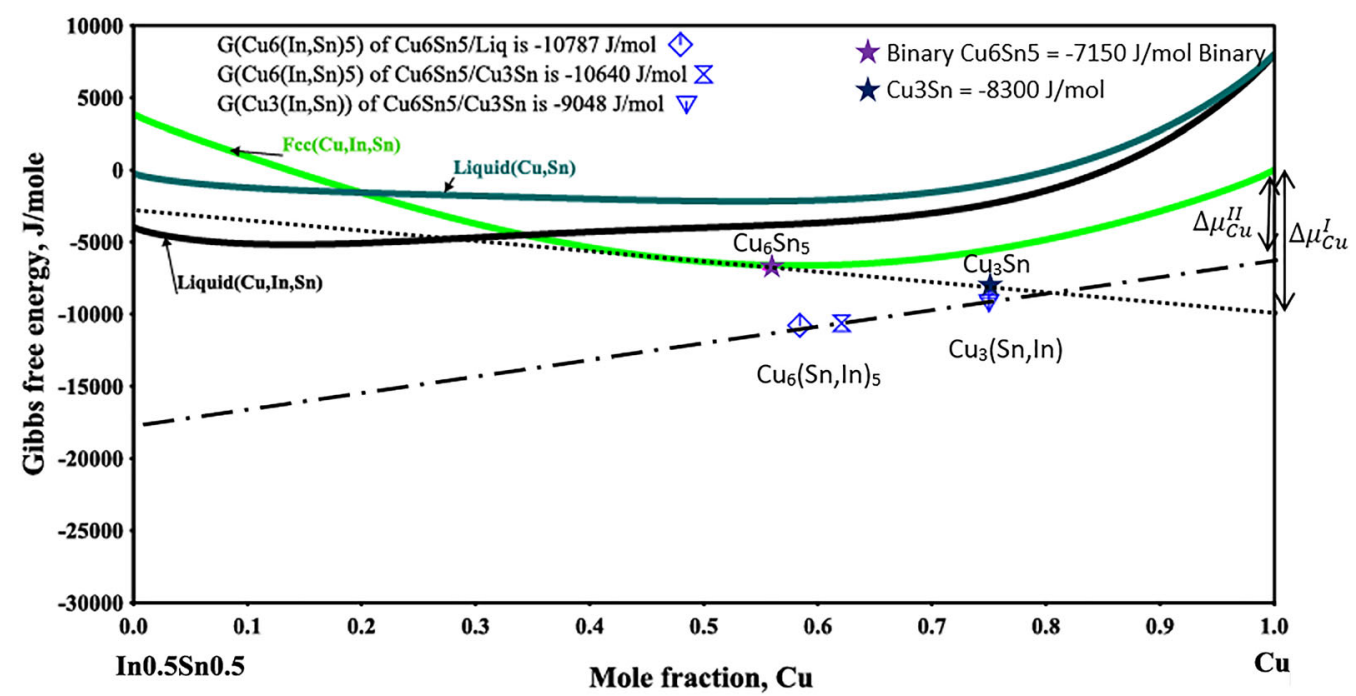

Fig. 6. Gibbs energy diagram from Cu-In-Sn system at $250^{\circ} \mathrm{C}$ along the contact line shown in Fig. 5 with superimposed liquid [Liquid(Cu,Sn)] curve from the binary Cu-Sn system. It is to be noted that the actual Gibbs energy values are calculated according to the local equilibria i.e. the tie lines representing the observed diffusion path. The In containing $\mathrm{Cu}_{6}(\mathrm{Sn}, \mathrm{In})_{5}$ has two values, one when it is in local equilibrium with liquid phase and the other when it is in local equilibrium with $\mathrm{Cu}_{3}(\mathrm{Sn}, \mathrm{In})$. The dotted and dash-dotted lines represent the local equilibria (common tangent construction) in binary and ternary systems, respectively. The other phases, which were not observed, were omitted from the figure. 
Table I. Chemical potentials for $\mathrm{Cu}$, In and Sn at different local equilibria in binary (Bin) Cu-Sn and ternary (Ter) Cu-In-Sn systems (J/mol)

\begin{tabular}{|c|c|c|c|c|}
\hline $250^{\circ} \mathrm{C}$ & Fcc-Cu ${ }_{41} \mathbf{S n}_{11}$ & $\mathrm{Cu}_{41} \mathrm{Sn}_{11}-\mathrm{Cu}_{3} \mathrm{Sn}$ & $\mathrm{Cu}_{3} \mathrm{Sn}-\mathrm{Cu}_{6} \mathrm{Sn}_{5}$ & $\mathrm{Cu}_{6} \mathrm{Sn}_{5}$-Liquid \\
\hline$\mu_{\mathrm{S}}^{\mathrm{Bin}}$ & \multicolumn{2}{|c|}{$-32450\left(\mathrm{Fcc}-\mathrm{Cu}_{3} \mathrm{Sn}\right)$} & -3370 & -350 \\
\hline$\mu_{\mathrm{Sn}}^{\mathrm{Ter}}$ & -39120 & -33790 & -23040 & -3860 \\
\hline$\mu_{\mathrm{Cu}}^{\mathrm{Bn}}$ & \multicolumn{2}{|c|}{$-250\left(\mathrm{Fcc}-\mathrm{Cu}_{3} \mathrm{Sn}\right)$} & -9950 & -12460 \\
\hline$\mu_{\mathrm{Cu}}^{\mathrm{Ter}}$ & -76 & -1540 & -5050 & -15430 \\
\hline$\mu_{\mathrm{In}}^{\mathrm{Te}}$ & -33880 & -28320 & -18110 & -4670 \\
\hline $\begin{array}{l}200^{\circ} \mathrm{C} \\
\mu_{\mathrm{Sn}}^{\mathrm{Bin}}\end{array}$ & \multicolumn{2}{|c|}{$-32650\left(\mathrm{Fcc}_{-} \mathrm{Cu}_{3} \mathrm{Sn}\right)$} & $\begin{array}{c}\mathrm{Cu}_{3} \mathrm{Sn}_{-} \mathrm{Cu}_{6} \mathrm{Sn}_{5} \\
-3370\end{array}$ & $\mathrm{Cu}_{6} \mathrm{Sn}_{5}-\mathrm{Liquid} / \mathrm{Bct}$ \\
\hline$\mu_{\mathrm{Sn}}^{\mathrm{Tn}}$ & -39080 & -31920 & -23050 & -2680 \\
\hline$\mu_{\mathrm{Cu}}^{\mathrm{Bn}}$ & \multicolumn{2}{|c|}{$-170\left(\mathrm{Fcc}-\mathrm{Cu}_{3} \mathrm{Sn}\right)$} & -9930 & -12740 \\
\hline$\mu_{\mathrm{C}}^{\mathrm{Ter}}$ & -45 & -2040 & -5040 & -16440 \\
\hline$\mu_{\mathrm{In}}^{\mathrm{Te}}$ & -35520 & -27750 & -18540 & -3910 \\
\hline $\begin{array}{l}150^{\circ} \mathrm{C} \\
\mu_{\mathrm{Sn}}^{\mathrm{Bin}}\end{array}$ & \multicolumn{2}{|c|}{$-32800\left(\mathrm{Fcc}-\mathrm{Cu}_{3} \mathrm{Sn}\right)$} & $\begin{array}{c}\mathrm{Cu}_{3} \mathrm{Sn}_{-} \mathrm{Cu}_{6} \mathrm{Sn}_{5} \\
-3360\end{array}$ & $\underset{0}{\mathrm{Cu}_{6} \mathrm{Sn}_{5}-\mathrm{Liquid} / \mathrm{Bct}}$ \\
\hline $\begin{array}{l}\mu_{\text {Sn }} \\
\mu_{\mathrm{Sn}}^{\mathrm{Ter}}\end{array}$ & -39000 & -30460 & -23110 & -1610 \\
\hline$\mu_{\mathrm{C}}^{\mathrm{Bn}}$ & \multicolumn{2}{|c|}{$-110\left(\mathrm{Fcc}^{\left.-\mathrm{Cu}_{3} \mathrm{Sn}\right)}\right.$} & -9920 & -12730 \\
\hline$\mu_{\mathrm{Cu}}^{\mathrm{Ter}}$ & -24 & -2550 & -5000 & -17480 \\
\hline$\mu_{\mathrm{In}}^{\mathrm{Ter}}$ & -37110 & -26510 & -19170 & -3110 \\
\hline
\end{tabular}

effects over the $\mathrm{Cu}_{3} \mathrm{Sn}$ phase can also be seen with the respect to the chemical potential for Sn. Note that in the ternary system the diffusion of indium also plays a role in the reactions, as it is occupying the same sublattice with $\mathrm{Sn}$ in the $\mathrm{Cu}-\mathrm{Sn}$ IMCs. Based on these significant effects of indium on the chemical potentials of $\mathrm{Sn}$ and $\mathrm{Cu}$, it is not surprising that the as-bonded microstructures in the ternary $\mathrm{Cu}-\mathrm{In}$-Sn system seem to be much more stable than those in the binary Cu-Sn system. This effect is also seen at the metastable $\mathrm{Cu}-\mathrm{Cu}_{3}(\mathrm{Sn}, \mathrm{In})$ interface, where $\mathrm{Cu}_{41} \mathrm{Sn}_{11}$ does not nucleate or grow to observable thickness, even after extensive solid state annealing.

\section{CONCLUSION}

In this work, it has been experimentally demonstrated that by introducing In to the $\mathrm{Cu}$-Sn metallurgy as an alloying element, it is possible to decrease the SLID bonding temperatures down to $200^{\circ} \mathrm{C}$ and achieve microstructurally stabile interconnections that have a re-melting temperature above $600^{\circ} \mathrm{C}$. The low bonding temperatures and reasonable processing times make the $\mathrm{Cu}-\mathrm{In}$-Sn based LT-SLID process attractive to many waferlevel bonding applications. Moreover, it would provide solutions that would not suffer from the CTE mismatch-induced residual stresses of traditional higher temperature wafer-level bonding methods. Additionally, based the assessed thermodynamic data, it was found that Indium stabilizes the liquid and $\mathrm{Cu}_{6} \mathrm{Sn}_{5}$ phases much more that the $\mathrm{Cu}_{3} \mathrm{Sn}$ phase. Therefore, the driving force (i.e. chemical potential difference) for $\mathrm{Cu}$ to diffuse through the $\mathrm{Cu} 3 \mathrm{Sn}$ phase is drastically reduced, hindering microstructural evolution. This, in turn provides high potential for enhanced long-term reliability for the interconnections; however, additional studies for mechanical reliability performance and defect formation are still required.

\section{ACKNOWLEDGMENTS}

This project has received funding from the ECSEL Joint Undertaking (JU) under Grant agreement No 826588. The JU receives support from the European Union's Horizon 2020 research and innovation programme and Belgium, Germany, Netherlands, Finland, Austria, France, Hungary, Latvia, Norway, Switzerland, Israel. The authors would also like to acknowledge the Innovation Funding Agency Business Finland (formerly Tekes) for financial support. The authors acknowledge the provision of facilities as well as technical support by Aalto University at OtaNano-Nanomicroscopy Center (Aalto-NMC).

\section{FUNDING}

Open access funding provided by Aalto University. This study was funded by ECSEL Joint Undertaking (JU) under Grant agreement No 826588.

\section{CONFLICT OF INTEREST}

The authors declare that they have no conflict of interest.

\section{OPEN ACCESS}

This article is licensed under a Creative Commons Attribution 4.0 International License, which per- 
mits use, sharing, adaptation, distribution and reproduction in any medium or format, as long as you give appropriate credit to the original author(s) and the source, provide a link to the Creative Commons licence, and indicate if changes were made. The images or other third party material in this article are included in the article's Creative Commons licence, unless indicated otherwise in a credit line to the material. If material is not included in the article's Creative Commons licence and your intended use is not permitted by statutory regulation or exceeds the permitted use, you will need to obtain permission directly from the copyright holder. To view a copy of this licence, visit http://creativecommons.org/licenses/by/4.0/.

\section{REFERENCES}

1. M. Tilli, M. Paulasto-Krockel, M. Petzold, H. Theuss, T. Motooka, and V. Lindroos, Handbook of Silicon Based MEMS Materials and Technologies, 3rd ed. (Amsterdam: Elsevier, 2020).

2. L. Sun, M. Chen, L. Zhang, P. He, and L. Xie, J. Alloy. Compd. 818, 1 (2020).

3. I. Welch, W.J.C.J. Chae, S.-H.L.S.-H. Lee, N. Yazdi, and K. Najafi, in Proceedings of 13th International Conference on Solid-State Sensors, Actuators and Microsystems (2005), pp. 1350-1353.

4. V. Dragoi, E. Cakmak, and E. Pabo, Rom. J. Inf. Sci. Technol. 13, 65 (2010).

5. A. Duan, K. Wang, K.E. Aasmundtveit, and N. Hoivik, in 4th Electronic System-Integration Technology Conference (ESTC) (2012).

6. W.P. Lin, C. Sha, and C.C. Lee, IEEE Trans. Compon. Packag. Manuf. Technol. 2, 903 (2012).

7. C. Lee, A. Yu, L. Yan, H. Wang, J.H. He, Q.X. Zhang, and J.H. Lau, Sens. Actuat. A-Phys. 154, 85 (2009).

8. J.C. Lin, L.W. Huang, G.Y. Jang, and S.L. Lee, Thin Solid Films 410, 212 (2002).

9. B.J. Grummel, Z.J. Shen, H.A. Mustain, and A.R. Hefner, IEEE Trans. Compon. Packag. Manuf. Technol. 3, 716 (2013).

10. C.C. Lee, C.Y. Wang, and G. Matijasevic, IEEE Trans. Compon. Hybrids Manuf. Technol. 16, 311 (1993).

11. V. Chidambaram, C. Bangtao, G.C. Lip, and D. Rhee Min Woo, J. Electron. Mater. 43, 2498 (2014).

12. F.S. Shieu, C.F. Chen, J.G. Sheen, and Z.C. Chang, Thin Solid Films 346, 125 (1999).

13. F. Shieu, Z. Chang, J. Sheen, and C. Chen, Intermetallics 8, $623(2000)$.

14. L. Deillon, A. Hessler-Wyser, T. Hessler, and M. Rappaz, J. Micromech. Microeng. 25, 125016 (2015).

15. Y.-C. Chen and C.C. Lee, Thin Solid Films 283, 243 (1996).

16. Q. Guo, F. Yu, H. Chen, and M. Li, J. Mater. Sci. Mater. Electron. 29, 3014 (2018).

17. J.F. Li, P.A. Agyakwa, and C.M. Johnson, Acta Mater. 58, 3429 (2010).

18. S.W. Yoon, M.D. Glover, and K. Shiozaki, IEEE Trans. Power Electron. 28, 2448 (2013).

19. K. Chu, Y. Sohn, and C. Moon, Scr. Mater. 109, 113 (2015).

20. H.P.R. Frederikse, R.J. Fields, and A. Feldman, J. Appl. Phys. 72, 2879 (1992).

21. T. Suni, H. Xu, V. Vuorinen, H. Heikkinen, S. Vahanen, A. Jaakkola, P. Monnoyer, and M. Paulasto-Krockel, in Microelectronics and Packaging Conference EMPC (2013), pp. $1-5$.
22. T.A. Tollefsen, A. Larsson, O.M. Lövvik, and K. Aasmundtveit, Metall. Mater. Trans. B Process. Metall. Mater. Process. Sci. 43, 397 (2012).

23. H. Xu, A. Rautiainen, V. Vuorinen, E. Österlund, T. Suni, H. Heikkinen, P. Monnoyer, and M. Paulasto-Kröckel, in 5th Electronics System-Integration Technology Conference, ESTC (2014).

24. H. Xu, T. Suni, V. Vuorinen, J. Li, H. Heikkinen, P. Monnoyer, and M. Paulasto-Kröckel, Adv. Manuf. 1, 226 (2013).

25. K. E. Aasmundtveit, T.T. Luu, H.V. Nguyen, R. Johannessen, N. Hoivik, and K. Wang, in Electronics System-Integration Technology Conference (ESTC) (2010), pp. 0-5.

26. S. Marauska, M. Claus, T. Lisec, and B. Wagner, Microsyst. Technol. 19, 1119 (2013).

27. T.A. Tollefsen, O.M. Løvvik, K. Aasmundtveit, and A. Larsson, Metall. Mater. Trans. A Phys. Metall. Mater. Sci. 44, 2914 (2013).

28. T.A. Tollefsen, A. Larsson, M.M. Visser Taklo, A. Neels, X. Maeder, K. Høydalsvik, D.A.G.W. Breiby, and K. Aasmundtveit, Metall Mater Trans B 44, 406 (2013).

29. A. Hilton and D.S. Temple, Sensors 16, 1 (2016).

30. P. Ramm, J. Ji, Q. Lu, and M.M.V. Taklo, Handbook of Wafer Bonding (New York: Wiley, 2012).

31. M. Brincker, S. Söhl, R. Eisele, and V.N. Popok, Microelectron. Reliab. 76, 378 (2017).

32. C.T. Ko and K.N. Chen, Microelectron. Reliab. 50, 481 (2010).

33. H. Liu, G. Salomonsen, K. Wang, K.E. Aasmundtveit, and N. Hoivik, IEEE Trans. Compon. Packag. Manuf. Technol. 1, 1350 (2011).

34. T.T. Luu, A. Duan, K.E. Aasmundtveit, and N. Hoivik, J. Electron. Mater. 42, 3582 (2013).

35. W.L. Chiu, C.M. Liu, Y.S. Haung, and C. Chen, Mater. Lett. 164, 5 (2016).

36. F. Brem, C. Liu, and D. Raik, in 4th Electronic System-Integration Technology Conference (ESTC) (2012).

37. B.H. Kwak, M.H. Jeong, J.W. Kim, B. Lee, H.J. Lee, and Y.B. Park, Microelectron. Eng. 89, 65 (2012).

38. H.J. Van De Wiel, A.S.B. Vardøy, G. Hayes, H. R. Fischer, A. Lapadatu, and M.M.V. Taklo, in 4th Electronic System-Integration Technology Conference (ESTC) (2012).

39. A. Rautiainen, H. Xu, E. Österlund, J. Li, V. Vuorinen, and M. Paulasto-Kröckel, J. Electron. Mater. 44, 4533 (2015).

40. A. Rautiainen, V. Vuorinen, and M. Paulasto-Kröckel, $M a-$ ter. Today Proc. 2, 7093 (2017).

41. A. Rautiainen, V. Vuorinen, H. Heikkinen, and M. PaulastoKröckel, IEEE Trans. Compon. Packag. Manuf. Technol. 8, 169 (2018).

42. A. Rautiainen, G. Ross, V. Vuorinen, H. Dong, and M. Paulasto-Kröckel, J. Mater. Sci. Mater. Electron. 29, 15212 (2018).

43. K. Puttlitz and K. Stalter, Handbook of Lead-Free Solder Technology for Microelectronic Assemblies (New York: Marcel Dekker, 2004).

44. S. Chen, S. Lin, and C. Yang, J. Electron. Mater. 35, 1 (2006).

45. X.J. Liu, H.S. Liu, I. Ohnuma, R. Kainuma, K. Ishida, S. Itabashi, K. Kameda, and K. Yamaguchi, J. Electron. Mater. 30, 1093 (2001).

46. W. Gierlotka, J. Electron. Mater. 41, 86 (2012).

47. S. Lin, T. Chung, S. Chen, and C. Chang, J. Mater. Res. 24, 2628 (2009).

48. J.O. Andersson, T. Helander, L. Höglund, P.F. Shi, and B. Sundman, Calphad 26, 273 (2002).

Publisher's Note Springer Nature remains neutral with regard to jurisdictional claims in published maps and institutional affiliations. 